\title{
A regulamentação do enfoque comercial no setor educacional via OMC/GATS*
}

\section{Ângela C. de Siqueira}

Universidade Federal Fluminense, Faculdade de Educação

\section{Introdução}

O objetivo deste texto é tentar explicar como e por que surgiu, no âmbito das regulamentações comerciais, o Acordo Geral sobre Comércio em Serviços (AGCS) - GATS em sua sigla em inglês -, assim como verificar os interesses para sua adoção no setor educacional e os possíveis riscos disso para a educação, a começar por sua redução a um serviço comercial qualquer, a ser normatizado com base nas regras gerais do comércio, o que afeta não só a concepção da educação como um direito social, mas também a identidade e a soberania dos países. De forma complementar, destaco, ao final, algumas reações emergentes que vêm surgindo diante de tais propostas e a necessidade de uma maior participação coletiva.

* Texto apresentado no III Seminário Nacional Educação \& Poder: tensões de um país em mudança, promovido pelo Programa de Pós-Graduação em Educação da Universidade Federal Fluminense, em Niterói, RJ, de 3 a 5 de setembro de 2003; revisto em janeiro de 2004.
Estima-se atualmente que, entre gastos governamentais e privados, o setor educacional movimente cerca de dois trilhões de dólares (Patrinos, 2002). Esse expressivo volume de recursos tem atraído o interesse crescente de diversos grupos, principalmente empresariais, da área de comunicação, de informática, de serviços e de educação com fins lucrativos. ${ }^{1}$

Os países mais ricos, com a maioria de sua população escolarizada, uma taxa de natalidade decrescente e amplos sistemas educacionais em funcionamento, estão se apresentando como um mercado restrito para a atuação de empresas no setor educacional. Por outro lado, os países em desenvolvimento onde hoje se encontra a maior parte da população em

${ }^{1}$ Por exemplo, General Electric, Motorola, McDonald's, Sun Microsystems, Fordstar, Microsoft, Appolo Group, Sylvan Learning Systems, De Vry Inc., Open Learning Agency of Australia, Open University Worldwide, Universitas 21, U21 \& Thompson Learning, Ecornell, NYU's School of Continuing and Professional Studies etc. (Rosenburg, 2002; Sauvé, 2002; WEM, 2002). 
idade escolar e, portanto, onde há uma grande demanda potencial para a oferta de ensino nos vários níveis são os alvos privilegiados dessa busca dos grupos empresariais por novos mercados.

Contudo, pelo fato de a educação ter se constituído, na maioria dos países, como um dos direitos sociais, a presença/oferta e o controle da mesma pelo Estado apresentam várias limitações à expansão comercial/mercadológica dos negociadores da educação, tratadas agora como "barreiras" que devem ser derrubadas. Dessa maneira, há uma crescente pressão para que a educação seja tratada, cada vez mais, como uma mercadoria como outra qualquer, regulada pelas normas supostamente "neutras e gerais" do mercado/ comércio, sem maiores interferências das regulamentações locais (barreiras).

A seguir apresento um breve histórico sobre a regulamentação do comércio.

\section{Regulamentação do comércio no pós Segunda Guerra Mundial}

Com o fim da Segunda Guerra Mundial (final dos anos de 1940), os líderes mundiais reunidos em Bretton Woods criaram duas instituições: o Banco Mundial (BM) e o Fundo Monetário Internacional (FMI). O primeiro surgiu para fornecer empréstimos destinados à reconstrução dos países destruídos pela guerra - o que não veio a fazer por falta de fundos - e, posteriormente, transformou-se em Banco de Desenvolvimento, destinado a emprestar recursos aos países em desenvolvimento. O FMI atuaria no controle das finanças dos países, via garantia do valor das moedas/reservas dos países, com base no "padrão-ouro". Havia a intenção de se criar uma Organização Internacional do Comércio, mas, em decorrência de divergências entre os países, tal fato não se concretizou. Contudo, foi criado o Acordo Geral Sobre Tarifas e Comércio, mais conhecido pela sua sigla inglesa GATT (General Agreement on Tariffs and Trade). O GATT, apesar de ter a denominação de acordo e não ser uma instituição, possuía uma sede própria e uma secretaria. Os países em desenvolvi- mento, no entanto, não aceitavam os seus princípios, tais como: o tratamento igual para todos, independente das diferenças/nível de desenvolvimento dos países, e as definições referentes aos produtos agrícolas (preços, padrões, exigências sanitárias etc.). Esses países sempre reclamaram de que o GATT trazia mais benefícios para os países mais industrializados, o que fez com que poucos tivessem aderido inicialmente a ele (Williams, 1994).

Cabe destacar, neste breve histórico, que data ainda desse mesmo período a criação das Nações Unidas e a promulgação da Declaração Universal dos Direitos Humanos e Sociais, que pregava a solidariedade e a colaboração recíproca entre os países, e não a competição.

Na década de 1960, os países em desenvolvimento começaram a ganhar mais força no cenário político/comercial e conseguiram a criação, em 1964, no âmbito das Nações Unidas, de um órgão para lidar com o comércio em bases mais favoráveis e no qual passariam a ter maior poder de decisão/pressão: a Conferência das Nações Unidas para o Comércio e Desenvolvimento (UNCTAD), que, aliás, nunca foi bem aceita pelos países mais desenvolvidos. No entanto, a UNCTAD foi fundamental para a aprovação, em 1974, pela Assembléia Geral da Organização das Nações Unidas (ONU) - UN, em inglês -, de um documento intitulado Nova Ordem Econômica Internacional, que previa mais cooperação, trocas, solidariedade entre os países, além de respeito à soberania e às diferenças sociais, culturais, religiosas, políticas, e o fim de formas de apartheid, de colonialismos e de neocolonialismos comerciais etc. (UN, 1974). Esses mesmos princípios foram defendidos pelos países em desenvolvimento na Rodada do GATT em Tokyo (1973-1979), que acabou por reconhecer os problemas e interesses dos países pobres e em desenvolvimento e introduzir o princípio de tratamento especial e diferenciado.

A formação da Organização dos Países Exportadores de Petróleo (OPEP) e as crises do petróleo (1974 e 1979), a derrota dos Estados Unidos (EUA) no Vietnã, sua influência na derruba do governo de 
Salvador Allende, no Chile, e o crescimento de movimentos antiintervencionistas foram outros fatores que levaram os países mais ricos a adotar uma postura de enfraquecer as Nações Unidas e suas instituições, via redução de recursos, principalmente a partir da década de 1980 (UN,1999). Em contraposição, as instituições de Bretton Woods foram reforçadas, tendo o BM e FMI passado a agir conjuntamente. O BM deixou de atuar como um Banco de Desenvolvimento e passou a atuar como um auxiliar na cobrança da dívida externa (Fried \& Owen, 1982), fazendo com que os países endividados adotassem ajustes estruturais, por meio de empréstimos denominados SALS e SECALS (empréstimos para ajustes estruturais nacionais e empréstimos para ajustes estruturais setoriais), privatizassem empresas públicas e abrissem seus mercados.

No âmbito do comércio, em 1986 foi iniciada uma rodada de negociações do GATT, denominada Rodada do Uruguai, que se estendeu até 1995. Nela houve a rejeição do princípio de tratamento especial e diferenciado aos países menos desenvolvidos, e sua substituição pelas regras do "livre" comércio, como desejado pelas grandes corporações, que contaram com o suporte de seus governos para abrir mercados e estabelecer normas comuns. Assim, como resultado da Rodada do Uruguai, foi criada a Organização Mundial do Comércio (OMC ou WTO), na sua sigla em inglês: World Trade Organization), que, além de incorporar o GATT como Acordo Geral que rege o comércio de bens materiais, estabeleceu acordos em outras áreas - conhecimento, investimentos e serviços -, com crescente perspectiva de lucros: respectivamente o Trade-related Aspects of Intellectual Property Rights (TRIPS), o Trade-related Investment Measures (TRIMS) e o General Agreement on Trade in Services (GATS).

Uma síntese sobre o significado da criação da OMC e seu impacto pode ser visto nos excertos a seguir:

A Organização Mundial do Comércio dá às regras comerciais uma estrutura organizacional permanente (po- deres que o GATT não tinha) e um tipo de "personalidade legal” desfrutada pela ONU, Banco Mundial e FMI. [No] "sistema de resolução de disputa" da OMC [...] as disputas não são decididas por representantes de governos democraticamente eleitos, mas por tribunais secretos, compostos por burocratas do comércio internacional. [...] As qualificações para os membros [...] incluem experiência em delegação comercial de algum país ou de advocacia em disputas comerciais $[\ldots]$ que geram painelistas com uma perspectiva uniforme, favorável ao comércio. (Nader \& Wallach, 1996, p. 102-103)

Qualquer país-membro pode questionar, através da OMC, qualquer lei de outro país que entenda estar privandoo dos benefícios esperados. [...] Embora [...] os questionamentos sejam apresentados por um país contra outros, o ímpeto para um questionamento vem normalmente de uma corporação transnacional. [...] Quando um questionamento acerca de uma lei nacional ou local é trazido ante à OMC, as partes contendoras apresentam seu caso em uma audiência secreta ante um painel de três peritos em comércio. [...] O ônus de prova está no acusado, que deve provar que a lei em questão não é uma restrição ao comércio como definido pelo GATT/OMC. (Korten, 1996, p. 176)

Mesmo não havendo a pretensão de tratar aqui do TRIPS, do TRIMS ou do GATT, mas apenas do GATS (ou ACGS - Acordo Geral sobre Comércio em Serviços), é importante ressaltar apenas que no âmbito da OMC impera a lógica do comércio/mercado: do lucro e da competição. Mais ainda, a OMC foi referendada como o "único fórum para a elaboração de regras globais de comércio e liberalização" (WTO, 2001c, p. 1), o que significa uma tentativa de desqualificação prévia de outros fóruns que apresentem uma lógica distinta sobre o comércio e/ou sobre serviços e suas limitações perante os direitos humanos e sociais.

\section{O objetivo, a regulamentação e a abrangência do GATS}

O GATS/AGCS foi assinado pelos paísesmembros da OMC em 1/1/1995, tendo como objetivo a liberalização progressiva dos serviços (WTO, 
1995, p. 278), com uma perspectiva de conclusão das negociações no prazo de dez anos (até 1/1/2005). No processo de negociação os países deveriam inicialmente apresentar propostas para a liberalização dos diversos setores de serviços, e posteriormente prosseguir com apresentação, de forma bilateral, de demandas específicas (o que deveria ocorrer até 30/6/ 2002) e a seguir ofertas (o que deveria ocorrer até 31/ 3/2003), havendo também reuniões ministeriais periódicas, como a de Doha, no Quatar, em novembro de 2001, e a de Cancun, no México, em setembro de 2003.

Isso significa a incorporação de diversos setores tradicionalmente mantidos e regulamentados pelo Estado como parte dos direitos sociais e subjetivos do cidadão, e fruto de anos de luta e conquistas (educação, saúde, meio ambiente, saneamento etc.) no âmbito do GATS, e seu ordenamento na lógica do lucro, da oferta e da competição, características do pensamento liberal do "livre" mercado.

A lista de serviços do GATS inclui 12 tipos, subdivididos em muitos outros: 1) Negócios (contabilidade, informática e afins, jurídico, propaganda e afins, serviços médicos e dentários, arquitetura etc.); 2) Comunicação (telecomunicação, correios, audiovisual, rádio etc.); 3) Construção e serviços de engenharia afins; 4) Distribuição ( franchising, varejo e atacado etc.); 5) Educação; 6) Ambientais; 7) Finanças; 8) Saúde e afins (hospital, social etc.); 9) Turismo, viagens e afins (hotel, restaurante, agência de viagens etc.); 10) Esporte, cultura e recreação; 11) Transportes (marítimo, aéreo, rodoviário, ferroviário, dutos, armazéns etc.); e 12) "Outros serviços não mencionados em qualquer outro lugar" (WTO, 2003). Este último item da lista permite a inclusão de qualquer outro serviço não listado e/ou que vier a existir no futuro.

Quando da assinatura do GATS, os paísesmembros da OMC concordaram com a inclusão de todos os serviços no Acordo, com a frágil "exceção daqueles que sejam caracterizados como fornecidos no exercício da autoridade governamental, e que não sejam oferecidos de forma comercial e nem entrem em competição com um ou mais provedores de servi- ços" (WTO, 1995, Art. I, 3, b-c). Ou seja, no que tange à educação, caso qualquer governo cobre qualquer taxa pelos serviços educacionais, ofereça cursos pagos diretamente, em convênios, ou desenvolva pesquisas e receba remuneração - o que é o caso em muitos países -, o mesmo estará ofertando serviços em bases comerciais e, portanto, estaria fora da exceção. Mais ainda, se o governo oferece cursos à distância e outros provedores privados fazem o mesmo, ele está em concorrência com esses outros fornecedores de serviços; portanto, estaria excluído também da excepcionalidade.

O mesmo Art. I, item 3, indica que as regras e os compromissos do GATS se aplicam aos governos dos países signatários - em todos os seus níveis (do local ao nacional) -, assim como às organizações nãogovernamentais que estejam executando atividades governamentais. O Acordo apresenta ainda várias regras gerais - dentre as quais deve-se destacar as de Nação Mais Favorecida (MFN, em inglês), Transparência, Regulamentação Doméstica, Reconhecimento e Restrições para Resguardar a Balança de Pagamentos - e regras de adesão "voluntária", dentre as quais destacam-se: Acesso ao Mercado e Tratamento Nacional.

A primeira regra, MFN, estabelece que nenhum país pode receber tratamento inferior ao dado a um outro. Isso significa que se um país permitir competição em um determinado setor, ou tenha acordos específicos bilaterais e/ou com um bloco de países (por exemplo, Mercosul, União Européia, acordo de Livre Comércio da América do Norte - NAFTA - etc.), os mesmos benefícios/direitos devem ser estendidos aos demais países. Cabe ressaltar que, quando o GATS foi assinado, os membros tiveram a permissão única de pedir isenção dessa regra, por prazo determinado, isto é, até 1/1/2005. Mas, conforme o Anexo do Art. II, essas isenções estão tendo sua pertinência revista e fazem parte das negociações atuais; ou seja, podem ser extintas antes de 2005. O Brasil e a França, por exemplo, têm um acordo específico, o Santos Dumont, que exime a autenticação consular de diplomas e documentos por autoridade do país recep- 
tor, o que agiliza o processo de revalidação de títulos. Tal acordo foi assinado como reconhecimento recíproco sobre a idoneidade das instituições outorgantes dos títulos de validade nacional. Contudo, com a expansão de instituições e cursos cujo objetivo maior é o lucro, a extensão do referido acordo a distintos países poderia gerar a entrada de uma avalanche de diplomas e títulos expedidos por instituições não-idôneas e/ou cursos sem validade nacional, como já existentes em muitos países, mas que aqui querem ter a equivalência dos títulos que, tanto no Brasil como na França, exigem um trabalho de pesquisa, discussão e redação acadêmicas mais aprofundado.

Em relação à regra de Transparência (Art. II), os países devem publicar todas as leis e normas relevantes aos serviços, assim como responder a pedidos de esclarecimentos de outros países sobre medidas tomadas em qualquer setor; e notificar qualquer alteração na legislação à $\mathrm{OMC}$, onde poderá ser contestada. E quem decide o que é relevante? A proibição/ liberação de produtos transgênicos, o nível de poluição, o passe estudantil, o acesso etc. Certamente os interesses dos grandes grupos empresariais, pautados nas regras do mercado, terão precedência sobre os direitos humanos e sociais (moradia, alimentação, educação, saúde, emprego, lazer etc.).

Com referência à Regulamentação Doméstica, o documento do GATS estabelece que a mesma deva ser administrada de forma racional, objetiva e imparcial, e que, para evitar que "medidas em relação aos requisitos e procedimentos de qualificação, nível técnico e de licenciamento não constituam barreiras desnecessárias ao comércio de serviços, o Conselho para o Comércio em Serviços deve, através de instâncias apropriadas que venha a criar, estabelecer quaisquer regras necessárias" (Art. VI). Mais ainda, tais regras deveriam assegurar que tais exigências se baseassem em critérios objetivos e transparentes, como competência e capacidade para oferecer o serviço, e que não fossem mais exigentes do que o necessário para assegurar a qualidade do serviço (WTO, 1995, p. 290). Por certo, firmas podem argüir junto ao painel de disputa da OMC, por exemplo, no caso da educação, sobre o que seriam "requisitos e procedimentos não mais exigentes do que o necessário" e que criam "barreiras desnecessárias", como exigir nível mínimo de qualificação formal de professores, regras para autorização, funcionamento e credenciamento de cursos, requisitos para validade de títulos expedidos, normas para contratação de pessoal etc.

No que concerne ao Reconhecimento (Art. VII), o texto do Acordo propõe que, quanto aos critérios e às normas para autorização, licenciamento ou certificação dos fornecedores de serviços, os países possam reconhecer a educação ou experiência obtida, as exigências atendidas e as licenças ou certificações dadas por um outro país. Também indica que um membro não deve usar o Reconhecimento como uma maneira de discriminar países ou uma forma dissimulada de restringir o comércio em serviços. Por fim, postula que o Reconhecimento deveria se basear em critérios aceitos multilateralmente e que os membros deveriam trabalhar em cooperação com organizações intergovernamentais e não-governamentais relevantes, visando o estabelecimento e a adoção de padrões internacionais e critérios de reconhecimento padronizados, válidos também para a prática de serviços relevantes e profissões (WTO, 1995, p. 291). Ou seja, esse item do GATS visa eliminar as exigências de validação de cursos, títulos e autorizações para o exercício profissional de cada país, substituindo-as por uma certificação internacional. A principal agência multilateral, atuando na unificação das regras de certificação nacional, principalmente na Europa, com o Conselho de Reitores das Universidades Européias (CRUE) e via o Acordo de Bolonha, tem sido a Organização das Nações Unidas para a Educação, a Ciência e a Cultura (UNESCO), que desde 2000 (The Task Force on Higher Education and Society, 2000), vem, cada vez mais, defendendo posições similares às expressas pelo Banco Mundial na área educacional, qual seja, de educação como investimento, e não mais como um direito para todos, e que, portanto, para facilitar o seu "comércio" em nível global, necessita acabar com as regras nacionais e os traços de identidade locais, abrin- 
do espaço para o surgimento de uma educação "mundializada", mais homogênea e facilmente vendável a distintos países. Processo que certamente acabaria por afetar a própria soberania das nações.

Quanto às Restrições para Proteger a Balança de Pagamentos (Art. XII), o Acordo estabelece que países com problemas na balança de pagamentos ou dificuldades financeiras externas poderiam adotar ou manter restrições no comércio de serviços. Contudo, as restrições, por exemplo, não podem ferir as regras do FMI; devem evitar danos desnecessários aos interesses comerciais, econômicos e financeiros de qualquer outro país; e não devem servir para proteger um determinado setor (WTO, 1995, p. 293).

Apesar de o texto indicar que devem ser respeitadas as diferenças e dificuldades dos países pobres, a legislação acima, principalmente a MFN, de regulamentação doméstica, e mesmo a da "proteção à balança de pagamentos", certamente impedem qualquer tratamento diferenciado baseado em princípios e necessidades diferentes dos critérios "objetivos e transparentes" do mercado e da sua busca de lucros. E essas regras são gerais; isto é, atingem a todos os signatários do Acordo.

Em relação às regras supostamente de adesão "voluntária", o Acesso ao Mercado (Art. XVI) estabelece que um país-membro não pode estabelecer limitações quanto: ao número de fornecedores, seja através de cotas, monopólios, provedores exclusivos ou exigências de prova de capacidade econômica; ao valor total das transações de serviços ou bens; ao número total das operações de serviço ou à quantidade total de serviço efetuado; ao número de pessoas físicas que podem ser empregadas em determinado serviço, ou que um fornecedor de serviços pode empregar e que são necessários; a participação de capital estrangeiro em firmas nacionais ou o valor total de investimento estrangeiro individual ou agregado; restrição ou exigência de formas específicas de organização legal ou joint venture (WTO, 1995, p. 297). Essa regra pode acelerar um processo de fusões, aquisições e desnacionalização de serviços básicos (por exemplo, educação e transporte), além de poder levar a uma competição desenfreada com vários fornecedores, buscando reduzir custos, e assim oferecendo serviços de baixa qualidade (cursos de menor duração, com professores menos qualificados, somente a distância etc.), explorando mais os trabalhadores (pagamento por tarefas, gravações, sem qualquer direito a férias, repouso remunerado etc.), o meio ambiente (construções em áreas de preservação, uso de produtos tóxicos e/ou equipamentos que trazem risco à população etc.), entre outros.

O Tratamento Nacional (Art. XVII) implica que não deve ser dado aos serviços e provedores estrangeiros tratamento inferior ao acordado com os serviços e provedores nacionais. E indica ainda que tratamento formalmente igual, ou diferente, podem ser considerados como menos favoráveis se modificarem as condições de competição em favor de serviços ou provedores nacionais a serviços similares ou fornecedores de qualquer outro país-membro. Isso significa que, caso o governo ofereça um serviço público, como transporte, educação, ou saúde, e esse seja entendido como entrando em competição ou sendo oferecido de forma comercial, pode ser exigido que o governo pare de oferecer tal serviço e/ou tenha que oferecer as mesmas condições aos provedores estrangeiros, como, por exemplo, prédios, pagamento de pessoal, bolsas para alunos, financiamento de pesquisas, combustível, garagem, manutenção etc.

Por fim, cabe ainda destacar que, nas negociações, o comércio dos serviços, inclusive os educacionais, encontra-se agrupado em quatro modos de oferta (WTO, 1995, Art. I, 2): o Modo 1 - oferta transfronteiras: a oferta de serviços por fornecedores com sede em um país para um outro país-membro (educação à distância, testes etc.); o Modo 2 - consumo no exterior: o consumo de serviços por indivídudos de um país em outros países-membros (por exemplo, cursos de línguas no exterior, pós-graduação, treinamentos etc.); o Modo 3 - presença comercial: a presença comercial de grupos em um país, via a instalação de campi, franchises no país de realização do serviço; o Modo 4 - presença de pessoas naturais: a presença de pessoas físicas de um país executando serviços em 
outros países (consultores, professores, administradores, pessoal para aplicação de testes etc.). Os países devem-se posicionar sobre se aceitam totalmente, parcialmente, ou não aceitam cada um desses modos, em referência a cada uma das categorias/subcategorias dos serviços.

\section{Particularidades sobre os serviços educacionais}

Em 1998 foi divulgado um documento sobre serviços educacionais, elaborado pelo Secretariado da OMC (WTO, 1998a). Seu contéudo, além de indicar a importância econômica da educação, principalmente para países que recebem muitos alunos estrangeiros (Estados Unidos, França, Alemanha, Reino Unido, Federação Russa, Japão, Austrália, Canadá, Bélgica e Suíça), revela o potencial de gastos com o comércio de serviços educacionais nos países com maior população em idade escolar (de 5 a 29 anos), destaca as mudanças que vêm ocorrendo no setor, onde a redução de recursos públicos tem provocado uma busca crescente de fontes alternativas de recursos e a adoção de práticas de administração empresarial. Esse mesmo texto relata o surgimento de novas instituições e formas de parcerias entre o público e o privado, citando o exemplo da Universidade dos Governos do Oeste, nos Estados Unidos, criada por 17 governos dos Estados do Oeste norte-americano, com parceiros privados como IBM, AT\&T, Cisco, Microsoft e Thomson. E vai além: ressalta que essa instituição não emprega qualquer professor ou desenvolve seus próprios cursos, mas adquire contéudos de professores empregados por outras instituições públicas ou privadas, que fornecem tais serviços. $\mathrm{O}$ atendimento aos alunos se dá via internet e outras tecnologias de educação à distância (WTO, 1998a, p. 5).

O documento apresenta a classificação dos "serviços" educacionais no âmbito da OMC/GATS: 1) serviços de educação primária (que inclui educação préprimária); 2) serviços de educação secundária (que inclui educação geral, preparatória para ensino técnico ou universitário; ensino técnico-profissionalizante e escolas profissionalizantes para alunos com neces- sidades especiais); 3) serviços de educação superior (pós-secundária, técnica, profissionalizante, bem como graduação e pesquisa); 4) educação de adultos (todo tipo de educação não-formal de adultos; alfabetização; educação por rádio, televisão, correspondência); 5) outros serviços educacionais/atividades de suporte educacional e/ou correlatas (educação formal de adultos, aconselhamento, consultorias, educação especial, testes de seleção/“avaliação", administração/ gerenciamento escolar, treinamento de professores, livros e materiais didáticos, construções escolares, serviços de limpeza, merenda escolar etc.) (WTO, 1998a, Anexo I). Na verdade, a definição do que sejam outros serviços educacionais por certo é objeto de disputa. Como se percebe, há a inclusão da educação em todos os seus níveis e modalidades, além dos ditos serviços de suporte e/ou correlatos (transporte, merenda, avaliação etc.) e sua oferta com base na lógica comercial, de mercado, isto é, do lucro.

$\mathrm{O}$ referido documento menciona barreiras ao comércio, agrupando-as pelo modo de oferta dos "serviços" educacionais. No que concerne ao consumo no exterior (Modo 1), aponta restrições diretas, como exigências do serviço de imigração e controle sobre recursos em moedas estrangeiras; e indiretas, onde menciona a equivalência nacional de títulos obtidos no exterior. Em relação ao estabelecimento de presença comercial (Modo 3), menciona a impossibilidade de obtenção de licenças nacionais, como, por exemplo, reconhecimento como instituição educacional autorizada a funcionar e com títulos reconhecidos; medidas que limitam os investimentos estrangeiros, como o teto máximo de capital estrangeiro na constituição de empresas; exigências quanto à nacionalidade; idoneidade financeira; restrições quanto ao emprego de professores estrangeiros; existência de monopólios governamentais e elevado subsídio a instituições nacionais. Quanto à presença de pessoas naturais (Modo 4), indica sobretudo as restrições dos serviços de imigração, nacionalidade, capacidade financeira e reconhecimento de credenciais (WTO, 1998a, p. 7). O texto não fez menção ao Modo 2, oferta transfronteiras, mas certamente aplicam-se limitações 
quanto às exigências de reconhecimento de títulos, número de provedores, idoneidade, conteúdos, qualificações, importações de material didático/instrucional de informática etc.

Apresenta ainda uma relação de 30 países que já tinham formulado algum compromisso em relação ao comércio dos serviços educacionais em 1998, sendo que 21 o apresentaram para a educação básica; 23, para a secundária; 21, para a superior; 20, para educação de adultos; e 12, para outros serviços (WTO, 1998a, Tabela 5).

Vejamos as propostas dos Estados Unidos (em 1988 e 2000), da Nova Zelândia e da Austrália (em 2001), e do Japão (em 2002), que são as únicas disponibilizadas pela OMC.

Os Estados Unidos enfatizaram na sua proposta o ensino superior, a educação de adultos (WTO, 2000, p. 1), os serviços de treinamento e de testes educacionais (p. 2), indicando que gostariam que os países adotassem as regras de tratamento nacional e de acesso ao mercado (p. 3). O documento aponta uma série de barreiras questionadas por esse país: proibição da oferta das três subcategorias de serviços por provedores estrangeiros e/ou não-obtenção de autorização para criar instituições no país-membro e/ou para que se qualifiquem como instituições credenciadas; restrições inapropriadas sobre transmissão eletrônica de materiais de cursos; prova de idoneidade econômica; medidas exigindo o uso de parceiros nacionais; negação de permissão para que provedores privados estabeleçam ou rompam livremente joint-ventures com parceiros nacionais ou estrangeiros; demora para a obtenção de autorização governamental, onde esta é exigida, e não explicação, em casos de negação da mesma; taxação desfavorável aos estrangeiros; tratamento menos favorável aos parceiros estrangeiros das joint-ventures do que o dado aos nacionais; tratamento menos favorável às franchises do que a outras formas de organização empresarial; leis e normas internas não claras e administradas de maneira injusta; subsídios para as três subcategorias não explicitados de forma clara e transparente; exigências para contratação de pessoal nacional desproporcionalmente elevadas; dificuldade de obtenção de permissão para a entrada e saída nos países de pessoal especializado (gerentes, especialistas de informática etc.) para serviço temporário; custo excessivo de impostos e/ou taxas para a conversão do capital a ser repatriado e altas taxas/impostos cobrados para a autorização de funcionamento/execução de serviços ou pagamento de royalty (WTO, 2000, p. 3-4).

A proposta da Nova Zelândia indica seu compromisso com a educação privada nos níveis primário, secundário e superior, e ressalta os "outros serviços" como área de interesse, propondo que se inclua na mesma cursos de curta duração de línguas e técnicos/vocacionais em várias áreas (informática, recepção, administração), assim como cursos de formação de motoristas e programas de treinamentos empresariais. Sugere ainda a inclusão de agências educacionais, que fazem, por exemplo, recrutamento e seleção de alunos (marketing, inscrições em programas etc.) (WTO, 2001a).

A proposta da Austrália menciona o ensino médio, o ensino superior e outros serviços educacionais, enfatizando ainda o Modo 1 - consumo no exterior. Também lista várias barreiras coincidentes com as listadas pelos Estados Unidos, com ênfase para as questões sobre vistos/imigração, assim como aponta o vínculo com outros setores: telecomunicações/audiovisual e movimentação de pessoas naturais, indicando, portanto, que a educação deveria ser vista nesse contexto mais amplo das negociações do GATS (WTO, 2001b). Vale mencionar que, segundo dados apresentados por um especialista do Banco Mundial, a Austrália vem se tornando um forte concorrente dos Estados Unidos na captação de alunos estrangeiros. Em 2000, os Estados Unidos tinham 450 mil alunos estrangeiros, enquanto a Austrália, que tinha cerca de 25 mil na década de 1980, passou para 100 mil em 1990 e atingiu cerca de 410 mil em 1999 (HolmNielsen, 2002).

A proposta do Japão (WTO, 2002) difere das apresentadas pelos países anglo-saxões mencionados, pois indica a necessidade de haver um "certo nível de liberalização", mas ressalta aspectos de política go- 
vernamental e especificidades do setor educacional que devem ser consideradas, tais como: a manutenção e garantia de qualidade da educação e das atividades de pesquisa em cada país-membro; a proteção aos estudantes, com medidas que assegurem que não serão lesados por serviços de baixa qualidade; e medidas que assegurem equivalência de títulos, diplomas etc. Critica a oferta de ensino por "fábricas-dediplomas" de um país em outro país, através de meio eletrônico; contudo, não deixa claro qual seria a "qualidade" a que se refere nesse contexto mercantil: ISOs? Qualidade padronizável e mensurável por testes?

As propostas supramencionadas são como uma carta geral de intenções, devendo os países apresentar demandas e ofertas específicas em negociações bilaterais, que são mantidas em segredo. Algumas demandas vazaram, como a da Comunidade Européia e a dos Estados Unidos. A demanda da Comunidade Européia, que inclui 109 países, inclusive o Brasil, não apresentou qualquer solicitação para a área de educação. Já a demanda dos Estados Unidos para a área de educação lista 31 países - inclusive o Brasil, e tratando a União Européia em bloco -, para os quais requer a adesão total às regras de acesso ao mercado e tratamento nacional, nos modos 1, 2 e 3 para ensino superior e treinamento, educação de adultos, "outros serviços" e testes (Sharma, 2002).

Num paralelo, vale ressaltar que a negociação da educação no âmbito da Área de Livre Comércio das Américas (ALCA) se pauta na mesma perspectiva de liberalização progressiva e ampliada (Aboites, 1999; Grieshaber-Otto \& Sanger, 2002). O Banco Mundial, através da Corporação Financeira Internacional/EdInvest (IFC, 2001), vem envidando esforços e organizando eventos (o primeiro foi na África, em 1999) a fim de promover a interação e o financiamento de grupos interessados no "negócio" educacional nos países em desenvolvimento (Siqueira, 2001). Até já existe uma feira internacional anual para a promoção do "negócio educacional": a World Education Market (WEM, 2002), que reúne representantes de governos "vendedores" de serviços educacionais (Nova Zelândia, Austrália, Estados Unidos,
Canadá, Finlândia, França etc.), assim como potenciais compradores (Brasil, Brunei, China, Chile, Nigéria, República Tcheca, Rússia etc.), empresários do setor educacional (Apollo Internacional, Sylva Learning Systems etc.), empresários de serviços educacionais (Centre d'Étude et Recherches sur les Qualifications), organismos internacionais (Banco Mundial, via IFC/Edinvest, UNESCO, Organização para a Cooperação e Desenvolvimento Econômico OCDE), empresários ligados ao setor de comunicação/informática (Cisco System, IBM, Sun Systems etc.), universidades (Auckland University, Nova Zelândia; University of British Columbia, Canadá; Finnish Virtual University, Finlândia; Université Paris III, Sorbonne Nouvelle etc.). Do Brasil participaram, entre outros representantes, os da Confederação Nacional da Indústria (Marcos Aranha e o senador Fernando Bezerra), do Colégio Bandeirantes, das Editoras Ática e Scipione, da Educare Informática, do Instituto Euvaldo Lodi, da Fundação Victor Civita (Guiomar Namo de Mello), da Promon Intelligens (Claúdia Costin, ex-MARE), do Ministério da Educação/Coordenadoria do Programa de Educação a Distância para Formação de Professores, do Serviço Nacional de Aprendizagem Industrial (SENAI), do Serviço Social do Comércio (SESC), do Serviço Social da Indústria (SESI), da Universidade Virtual Brasileira.

\section{Reações}

As maiores reações à inclusão da regulamentação da educação no âmbito do GATS estão ocorrendo na União Européia. A partir da realização do I Fórum Social Europeu (FSE), em 2002, foi lançada a idéia de que deveria haver um Fórum Europeu de Educação, realizado nos dias 18 e 19 de setembro em Berlim, na Alemanha, como espaço alternativo à Conferência dos Ministros de Educação da Europa. Para isso foram realizadas reuniões em vários países: em junho foi na Alemanha; em julho, na Suíça; em agosto, na França. Houve manifestação em Berlim, no dia 20 de setembro, principalmente em relação à criação de standards para credenciamento e qualificações 
(Acordo de Bolonha). No II FSE, em novembro, na França, os grupos pró-educação como um direito social, também questionaram o GATS na educação.

Em 23 de agosto de 2003 foi lançado um abaixoassinado internacional pela retirada da educação do GATS. Grupos em diversos países vêm-se articulando através de encontros, criação de listas de discussão e websites para disponibilização de material. ${ }^{2}$

${ }^{2}$ GATScrit; GATSwatch; Education is not for sale; Rightto-education; Global Services Network; Challengeglobalization; ITAPI - Tradeobservatory; Polaris Institute; Third World Network; Jubileesouth; Corpwatchindia; Transattac; Alternative Liste Duisburg (Alemanha); Appel pour une école démocratique (Bélgica); Asociación de Estudiantes de Derecho, Universidad Autonoma de Madrid (Espanha); AstA Uni Düsseldorf, Essen, Kassel, Mainz, Münster, Wuppertal (Alemanha); Attac Berlin, Hamburg, Düsseldorf, Potsdam (Alemanha); Attac France (França); Attac-Universiteit Gent (Bélgica); Campaign for Free Education (Reino Unido); Casa Diritti Sociali (Itália); Sindicato de Enseñanza de Sevilla (Espanha); DIDAweb - Comunità di educatori in rete (Itália); Die sozialistische Jugend (Alemanha); Escuela Libre Paideia (Espanha); Movimento Di Cooperazione Eductiva (Itália); Focus on the Global South (Tailândia); Il Gruppo Saperi del Social Forum di Firenze (Itália); Initiative Berliner Sozialforum (Alemanha); Internacional de la Educación (Bélgica); Internationale Socialisters Ungdom (Dinamarca); Kritische StudentInnen Utrecht (Países Baixos); Kulturattac (Alemanha); Laent - Laboratorio apprendimento e nuove tecnologie, Capoterra (Itália); Lithuanian National Union of Students (Lituânia); Movement for Modern School (Bulgária); Public Interest Advocacy Centre (Austrália); Redazione della rivista italiana di scuola "écolle" (Itália); ReferentInnenRat der Humboldt Universität zu Berlin (Alemanha); Scudag Network (Alemanha); SDAJ Münster (Alemanha); Sindacato Italiano Unicobas Scuola (Itália); Socialist Worker Student Society (Reino Unido); Studentska sekcija Foruma mladih SDP-a Hrvatska (Croácia); Klub studenata Hrvatskih studija Sveucilista u Zagrebu (KSHS), Hrvatska (Croácia); Syndicat français SUD Etudiant (França); Union des Etudiantes de Suisse (UNES) (Suíça); Universal Proutist Student Federation (UPSF) (Worldwide); Unione Svizzera degli Universitari (USU) (Suíça); Verband Sozialistischer StudentInnen Österreich (Áustria); World Development Movement, Londres (Inglaterra).
Em contrapartida, os grupos interessados na comercialização da educação, alguns deles mencionados na Introdução, contam com a pressão dos organismos citados, além da Global Alliance for Transnational Education (GATE); World Education Market; Banco Mundial: EdInvest/IFC; Heritage Foundation; US Coalition of Service Industries (USCI), entre outros.

$\mathrm{Na}$ reunião ministerial do GATS em Cancun, México, de 10 a 14 de setembro de 2003, 22 países em desenvolvimento, entre eles quatro grandes em extensão e população - Brasil, Argentina, Índia e China -, uniram-se formando um grupo denominado G-22, reivindicando a negociação de produtos agrícolas, o que não era aceito pelos Estados Unidos e pela União Européia. Dessta forma, criou-se um impasse, e a pauta geral de negociações foi bloqueada. No momento, os Estados Unidos pressionam os países em desenvolvimento que aderiram ao G-22, buscando acordos bilaterais. Cabe destacar o risco de que os "serviços" virem moeda de troca a algum tipo de concessão na área agrícola por parte dos Estados Unidos e da União Européia.

\section{Conclusões}

A perspectiva da educação na agenda do GATS, como um serviço comercial, implica a não-existência de barreiras para seu "livre comércio". Há cláusulas gerais às quais os países-membros estão automaticamente sujeitos, como, por exemplo, a de estender a todos os países signatários o mesmo tratamento dado à nação mais favorecida, a de não ter normas internas muito exigentes, a de aceitar os títulos e as qualificações obtidos no exterior etc. As cláusulas de "adesão voluntária" (tratamento nacional e acesso ao mercado), ao que parece, se depender dos Estados Unidos deverão ser aceitas sem restrições. Ou seja, não deverá haver tratamento diferenciado para grupos nacionais e estrangeiros, tenham eles sede ou não no país, empreguem ou não mão-de-obra nacional, desenvolvam ou não cursos de acordo com a realidade nacional. Nesse caso, a oferta de subsídios, isenções de impostos, programa de bolsa de estudos hoje existentes para instituições privadas educacionais nacionais po- 
derá ser requerida para todos os grupos estrangeiros que aqui estabeleçam negócios.

Quanto ao setor público, quanto mais terceiriza atividades (por exemplo, alimentação, treinamento de professores, avaliação etc.), vende serviços (cursos e tratamentos pagos, desenvolvimento de pesquisas remuneradas ou que beneficiem empresas), faz marketing comercial para atrair interessados, torna-se extremamente vulnerável à regulamentação da educação como um serviço comercial via OMC/GATS, saindo do frágil escudo do "exercício da autoridade governamental", pois passa a oferecer educação em base comercial e em competição com outros provedores. Assim sendo, os grupos empresariais poderão processar os países por práticas prejudiciais à livre oferta de serviços educacionais, em vista do oferecimento de tratamento diferenciado, caracterizado por subsídios às entidades públicas, exigindo tratamento igual: recursos públicos para todos ou para nenhuma instituição.

Com a educação no GATS corre-se o risco da sua transformação em um processo de simples comercialização, onde grupos internacionais ou grupos nacionais a eles coligados seriam os vendedores, enquanto os países, principalmente os em desenvolvimento, passariam a ser meros compradores de pacotes de serviços diretos (por exemplo, cursos profissionalizantes, de graduação, aperfeiçoamento e pós-graduação etc.) e complementares (por exemplo, sistemas de avaliação e certificação), além de "bens de consumo educacionais" (por exemplo, livros e materiais didáticos, cadernos, lápis, mapas, equipamento científico, uniformes etc.). Tal perspectiva fere a soberania e a autonomia das nações, num caminho que pode levar à perda da diversidade cultural e dos valores locais.

ÂNGELA C. DE SIQUEIRA, doutora em educação pelo International/Intercultural Development Education Program, da Florida State University/College of Education, com a tese The new economic global order and its effects on higher education policies, defendida em 2001, é professora adjunta da Faculdade de Educação da Universidade Federal Fluminens (UFF). Publicações recentes: Multilateral agencies and their policy proposals for education: are they contributing to reduce the knowledge gap in the world? (ERIC DATABASE- EUA- ED472147 agosto de 2003); O documento conjunto Banco Mundial - UNESCO sobre ensino superior (Revista Avaliação/Separata CIPEDES, Campinas, UNICAMP e RAIS, v. 6, n 1 , março de 2001, p. 3-8); O novo discurso do Banco Mundial e seu mais recente documento de política educacional (ANPEd - 24 ${ }^{a}$ Reunião Anual, Caxambu, MG, 7 a 11 de outubro de 2001, CD-ROM). Pesquisa atual: O avanço da perspectiva comercial no setor educacional: problemas e perspectivas. E-mail: asiquei@nitnet.com.br

\section{Referências bibliográficas}

ABOITES, H. (1999). Viento del norte. TLC y privatización de la educación superior en México. $2^{\mathrm{a}}$ ed. México: Universidade Autônoma Metropolitana-Xochimilco/Plaza y Valdez.

FRIED, E., OWEN, H.D. (eds.), (1982). The future role of the World Bank. Washington, DC: The Brookings Institution.

GRIESHABER-OTTO, J., SANGER, M., (2002). Perilous lessons: the impact of the WTO Service Agreement (GATS) on Canadian Public Education. Canada: Canadian Center for Policy Alternatives. HOLM-NIELSEN, L., (2002). Trade in education... why are we here? Texto apresentado no Forum OECD-US, painel "How can the global demand for post-secondary education be met...”. Washington, DC, mar.

IFC - International Finance Corporation, (2001). Investing in private education: IFC's strategic directions. Washington, DC: The World Bank Group, jun.

KORTEN, D.C., (1996). When corporations rule the world. Connecticut: Kumarian Press/San Francisco: Berrett-Koehler.

NADER, R., WALLACH, L., (1996). GATT, NAFTA and the subversion of the democratic process. In: MANDER, J., GOLDSMITH, E. (eds.). The case against the global economy. San Francisco: Sierra Club, p. 92-107.

PATRINOS, H.A., (2002). Promoting access to postsecondary education: meeting the global demand. Texto apresentado no Fórum US-OECD Traits of a Global Market for Advanced Human Capital. Washington, DC: World Bank.

ROSENBURG, C., (2002). O meganegócio da educação. Revista Exame, São Paulo, ano 36, $n^{\circ} 7,3$, abr.

SAUVÉ, P., (2002). Trade, education and the GATS: what's in, what's out, what's all the fuss about. Higher Education 
Management and Policy, v. 14, $\mathrm{n}^{\circ}$ 3. Disponível em: http:// www.oecd.org/pdf/M00029000/M00029613.pdf. Acesso em: 20 jun. 2003.

SHARMA, S., (2002). GATS education requests - US. Disponível em: GATSCrit@yahoogroups.com mailing list. “Shefali Sharma: ssharma@iatp.org. Acesso em: 7 nov. 2002.

SIQUEIRA, A., (2001). O novo discurso do Banco Mundial e seu mais recente documento de política educacional. In: $24^{\mathrm{a}} \mathrm{REU}-$ NIÃO ANUAL DA ANPED. CD-ROM.

THE TASK FORCE ON HIGHER EDUCATION AND SOCIETY, (2000). Higher education in developing countries: peril and promise. Washington, DC: IBRD/The World Bank Group.

UN - United Nations, (1974). Declaration on the establishment of a new international economic order. Resolution 3.201 (SVI). New York: United Nations, General Assembly, Sixth Special Session.

, (1999). The UN financial crisis. Setting the record straight, DPI/1815/Rev.16. New York: United Nations Department of Public Information. Disponível em: http:// www.un.org/News/facts/finance.htm. Acesso em: 10 ago. 2000.

WEM - World Education Market, (2002). World Education Market Conference: program presentation. Lisboa, Portugal. Disponível em: www.wemex.com. Acesso em: 2 jun. 2002.

WILLIAMS, M., (1994). International economic organisations and the third world. Great Britain: Harverster/Wheatsheaf.

WTO - World Trade Organization, (2001b). Communication from Australia. Negotiating proposal for education services. S/CSS/ W/110, out. Disponível em: www.wto.org/tratop_e/serv. Acesso em: 15 jul. 2003.
, (2002). Communication from Japan. Negotiating proposal for education services. S/CSS/W/137, mar. Disponível em: www.wto.org/tratop_e/serv. Acesso em: 15 jul. 2003.

,(2001a). Communication from New Zealand. Negotiating proposal for education services. S/CSS/W/93, jun. Disponível em: www.wto.org/tratop_e/serv. Acesso em: 15 jul. 2003.

(1998b). Communication from the United States: education services. S/C/W/55. Disponível em: www.wto.org/ tratop_e/serv_e. Acesso em: 15 jul. 2003. , (2000). Communication from the United States: higher (tertiary) education, adult education and training. S/CSS/W/23. Disponível em: www.wto.org/tratop_e/serv_e. Acesso em: 15 jul. 2003.

, (1998a). Education services. Background notes by the secretariat - S/C/W/49. Disponível em: www.wto.org/ tratop_e/serv_e/sanaly_e.htm. Acesso em: 10 ago. 2002.

, (1995). The General Agreement on Trade and Services (GATS): objectives, coverage and disciplines. Disponível em: www.wto.org/tratop_e/serv_e/gatsqa_e.htm. Acesso em: 10 ago. 2002.

, (2001c). Ministerial declaration (Doha). WT/ MIN(01)/DEC/1, nov. Disponível em: www.wto.org. Acesso em: 15 jul. 2003. , (2003). Services sectoral classification list. Relação disponível em: http://www.wto.org/english/tratop_e/serv_e/ gns_w_120_e.doc. Acesso em: 15 jul. 2003.

Recebido em outubro de 2003 Aprovado em fevereiro de 2004 
to make an incursion into a highly incomplete field, presenting some partial results of a study undertaken in 2000-2001, with 25 families of average to successful entrepreneurs from Minas Gerais. The aim of the study was to learn about the young people's school history and the educational strategies used by their parents during that time. A corpus of 50 interviews conducted with the youngsters and their mothers was compiled. Our conclusions allow us to question the current belief that the pattern of school excellence is a privilege of "the rich", or in other terms, that school élites are composed of "rich" students.

Key-words: school trajectory; family educational strategies; school/family relations

Ângela C. de Siqueira

\section{A regulamentação do enfoque comercial no setor educacional via OMC/GATS}

Aponta o crescente interesse de grupos empresariais na área educacional, perante o grande volume de recursos nela envolvidos, apresentando a perspectiva de inclusão da educação, como serviço, na agenda do Acordo Geral Sobre Comércio em Serviços, regido pela ótica da Organização Mundial do Comércio. Para tanto, analisa documentos da OMC, do GATS, propostas apresentadas por alguns países, evidenciando o interesse destes na eliminação de "barreiras" para seu "livre comércio". Sinaliza que a existência de regulamentações nacionais e mesmo a oferta do ensino público podem ser questionados como práticas prejudiciais à livre oferta de serviços educacionais, sujeitos às sanções da OMC, entre as quais os grupos empresariais poderão vir a exigir recebimento de recursos públicos e outros benefícios. Alerta para o fato de que, caso o GATS se concretize, correse o risco da transformação da educa- ção de direito público subjetivo em simples comercialização de pacotes educacionais (cursos, sistemas de avaliação e certificação, livros, uniformes, mapas etc.). Conclui, indicando que tal perspectiva fere a soberania e autonomia das nações, em um caminho que pode levar à perda da diversidade cultural e de valores locais, em benefício de um processo de homogeneização cultural, o que vem sendo contestado com a emergência de movimentos contrários.

Palavras-chave: comercialização da educação; privatização; Organização Mundial do Comércio; Acordo Geral sobre Comércio em Serviços

The regulation of the commercial approach to the educational sector by WTO/ GATS

The text indicates the entrepreneurial groups'growing interest in the educational field given the large amount of resources involved, presenting the perspective of including education, as a service, on the agenda of the General Agreement on Trade in Services, as a World Trade Organisation directive. To this end, it analyses WTO and GATS documents, as well as proposals presented by some countries, demonstrating their interests in eliminating "barriers" to "free trade" in education. The text points out that the existence of national regulations and even the offer of public education can be challenged as practices which are harmful to the "free" offer of educational services and subject to WTO sanctions allowing business groups to demand public resources and other benefits. Should GATS succeed, it runs the risk of converting education from a subjective public right into a process of simple commercialisation of educational packages (e.g. courses, systems of evaluation and certification, textbooks, uniforms, maps etc.). It concludes by indicating that such a perspective clearly endangers national sovereignty and autonomy, leading potentially to the loss of cultural diversity and local values, to the benefit of a process of cultural homogeneity. Notwithstanding, it also highlights the emergence of movements opposing this tendency. Key-words: commercialisation of education; privatisation; World Trade Organisation; General Agreement on Trade in Services

Munir Fasheh

Como erradicar o analfabetismo sem erradicar os analfabetos?

O texto desafia várias suposições que estão freqüentemente embutidas nas discussões oficiais sobre alfabetização, questionando o valor inerentemente libertador e positivo do processo de alfabetização, com base na necessidade de respeitar e revalorizar a diversidade de formas de aprender, estudar, conhecer e se expressar. Argumenta que liberação e liberdade estão articuladas à diversidade e ao pluralismo e que a educação representa apenas uma das formas de aprender. Afirma que o universalismo, mais do que qualquer outra coisa, tem sido a causa principal para se eliminar a diversidade considerada a essência da vida. Sugere que a adoção da alfabetização como forma dominante de conhecimento pode contribuir para o desaparecimento da diversidade e para a predominância de um único caminho para o progresso e o desenvolvimento. Palavras-chave: analfabeto; alfabetização; linguagem; conhecimento; diversidade

How to erradicate illiteracy without erradicating illiterates?

The text challenges various suppositions which are frequently included in official discussions on literacy, questioning the inherent liberating and positive value of the literacy process on the basis of the 